\title{
Síndrome CINCA: um Diasnóstico Diferencial da Artrite Idiopática Juvenil
}

\section{CINCA Syndrome: a Differential Diasnosis of the Juvenile Idiopathic Arthritis}

\author{
Erica Naomi Naka ${ }^{(1)}$, Ligia Maria Leme ${ }^{(2)}$, Maria Eulina Quilião ${ }^{(3)}$
}

\section{RESUMO}

A síndrome CINCA (crônico-infantil-neurológica-cutâneaarticular) é uma enfermidade inflamatória multissistêmica rara, de início no período neonatal e caracterizada por febre, exantema cutâneo, envolvimento articular e do sistema nervoso central. É também conhecida pela literatura médica norte-americana como NOMID (doença multissistêmica inflamatória de início neonatal). Relatamos o caso de uma criança de 3 anos de idade admitida em nosso serviço com história de febre e exantema cutâneo desde o período neonatal. Apresentou crises convulsivas no sexto mês de vida e artrite simétrica de joelhos desde o nono mês. Na admissão, mostrava-se toxemiada, pálida, com um exantema maculopapular generalizado e artrite de joelhos e tornozelos. Apresentava ainda retardo de crescimento e desenvolvimento. Achados laboratoriais incluíram anemia, leucocitose, trombocitose, níveis elevados de proteína $\mathrm{C}$ reativa e meningite asséptica no exame do liquor. Os outros exames foram negativos. Os achados radiográficos dos joelhos, quadris e tornozelos foram anormais. A criança recebeu tratamento com antiinflamatório não hormonal, corticosteróide e metotrexato, com melhora apenas da dor e da febre. A etiologia da síndrome CINCA permanece desconhecida e nenhum tratamento tem se mostrado eficaz. Essa doença deve ser distinguida da forma sistêmica da artrite idiopática juvenil (AIJ), o principal diagnóstico diferencial.

Palavras-chave: síndrome CINCA, NOMID, síndrome inflamatória multissistêmica, artrite idiopática juvenil.

\section{INTRODUÇÃO}

A síndrome CINCA (crônico-infantil-neurológicacutânea-articular) foi descrita na Europa, em 1981, por Prieur-Griscelli, como uma enfermidade inflamatória multissistêmica de início na infância ${ }^{(1-6)}$. É também co-

\begin{abstract}
CINCA syndrome (chronic-infantile-neurological-cutaneousarticular) is a rare multisystemic inflammatory disease with neonatal onset characterized by fever, skin rash, articular, and central nervous system involvement. This syndrome is known in the North American medical literature as infantile onset multisystem inflammatory disease (NOMID). We describe the case of a 3-yearold child admitted in our service with fever and skin rash since the neonatal period. She presented seizures at 6 months-old and bilateral arthritis of the knees since her 9 months. On admission she looked sick, pale and presented generalized erythematosus maculopapular rash, arthritis of the knees and ankles. She presented growth and mental retardation too. Laboratory findings included anemia, leukocytosis, thrombocytosis, elevated $C$-reactive protein levels and the examination findings from the cerebrospinal fluid showed an aseptic meningitis. Other test results were negative. Radiographs of the knees, hips and ankles revealed abonrmalities. The child received treatment with nonsteroidal anti-inflammatory drugs, corticosteroids and methotrexate, with partial response to treatment, leading to improvement in pain and fever defervescence. The etiology of CINCA syndrome remains unknown and no single treatment has been found to be effective. This disease should be distinguished from systemic onset juvenile idiophatic arthritis (JIA), the main differential diagnosis.
\end{abstract}

Keywords: CINCA syndrome, NOMID, multisystemic inflammatory syndrome, juvenile idiophatic arthritis.

nhecida pelos norte-americanos como NOMID (neonatal onset multisystem inflammatory disease) $)^{(7-10)}$. Inicia-se no período neonatal, caracterizada por febre, meningite crônica, uveíte, perda neurossensorial da audição e artropatia deformante ${ }^{(3,7)}$. São poucos os casos relatados mundialmente e no Brasil até o momento ${ }^{(11)}$. Essa doença é rara

\footnotetext{
Recebido em 10/09/06. Aprovado, após revisão, em 05/06/07. Declaramos a inexistência de conflitos de interesse.

Unidade de Reumatologia Pediátrica do Serviço de Reumatologia do Hospital Universitário da Faculdade de Medicina da Universidade Federal de Mato Grosso do Sul.

1. Mestra e responsável pela Unidade de Reumatologia Pediátrica do Serviço de Reumatologia do Hospital Universitário da Faculdade de Medicina da Universidade Federal de Mato Grosso do Sul.

2. Doutora e professora-assistente de Radiologia Médica da Faculdade de Medicina da Universidade Federal de Mato Grosso do Sul.

3. Neurologista pediatra da Apae e do Centro de Especialidades Médicas da Prefeitura Municipal de Campo Grande (MS).

Endereço para correspondência: Erica Naomi Naka, Rua Paulo Freire, 224, CEP 79080-140, Campo Grande, MS, fone: (67) 3027-5100, fax: (67) 9258-0642,

e-mail: nakaerica@yahoo.com.br
} 
e confundida com a forma sistêmica da artrite idiopática juvenil (AIJ), sendo comum o atraso no diagnóstico ${ }^{(9)}$. Apesar de não existirem ainda critérios bem definidos e esquema terapêutico padronizado, o diagnóstico precoce é importante para diminuir as seqüelas da doença.

Relatamos o caso de uma criança que apresentava exantema generalizado desde o primeiro mês de vida, febre diária desde os 8 meses e artropatia desde os 9 meses. $\mathrm{O}$ diagnóstico foi feito aos 3 anos de idade. O objetivo deste relato é sugerir o diagnóstico da síndrome CINCA quando as manifestações clínicas forem analisadas em um contexto clínico pertinente.

\section{RELATO DE CASO}

DNS, sexo feminino, branca, nascida de parto normal, a termo, com peso de $3.150 \mathrm{~g}$ e estatura de $48 \mathrm{~cm}$. Desde 1 mês de vida, apresentava exantema em todo o corpo e febre diária a partir do $8^{\circ}$ mês de vida. Aos 9 e 14 meses foram referidas duas crises convulsivas febris, tônicoclônicas generalizadas, controladas completamente com o uso de fenobarbital, via oral, $4 \mathrm{mg} / \mathrm{kg} /$ dia. Aos 9 meses, teve início artrite simétrica de joelhos, dolorosa à palpação e à movimentação, evoluindo para poliartrite em mãos, punhos, cotovelos e tornozelos.

O primeiro exame neurológico foi realizado no $12^{\circ}$ mês de vida, quando se observou atraso do desenvolvimento neuropsicomotor, com incapacidade para deambular, hipotonia e postura de batráquio, sentando-se apenas com apoio. Aos 2 anos de idade foi encaminhada ao Ambulatório de Reumatologia Pediátrica do Hospital Universitário da UFMS com diagnóstico de síndrome genética a esclarecer e retardo pôndero-estatural (percentil de peso e altura menor que 2,5). O diagnóstico inicial na admissão foi de artrite idiopática juvenil. Ao exame físico, observaram-se irritabilidade e exantema generalizado e pruriginoso que se exarcebava durante a febre (dois a três picos diários) (Figura 1). Ao exame osteoarticular, apresentava aumento de volume em joelhos, tornozelos, cotovelos, punhos e articulações interfalangeanas das mãos, com limitação à flexão e à extensão (Figura 2). Os exames laboratoriais mostraram anemia, leucocitose, plaquetose, provas inflamatórias elevadas $(\mathrm{PCR}=87,2 \mathrm{mg} / \mathrm{l}$, VHS $=81 \mathrm{~mm} / \mathrm{h}$, mucoproteínas $=11,5 \mathrm{mg} / \mathrm{dl}$, alfa $\mathrm{l}$ glicoproteína ácida $=273,6 \mathrm{mg} / \mathrm{dl}$ ). A dosagem de fosfatase alcalina $(726)$ e de $\operatorname{IgE}(744,1)$ estava elevada. A dosagem de outras imunoglobulinas ( $\operatorname{IgG}, \operatorname{IgM}, \operatorname{IgA}, \operatorname{IgD})$, cálcio e fósforo sérico foi normal. O fator antinúcleo (FAN), fator reumatóide (FR), enzimas musculares, provas de funções renal e hepática, dosagem de complemento, líquido cerebroespinal e cariótipo foram normais. As sorologias para doença crônica intra-útero foram negativas, exceto por dosagem elevada de IgG para citomegalovírus. O eletroencefalograma, a tomografia computadorizada (TC) e a ressonância magnética (RM) de crânio não evidenciaram alterações.

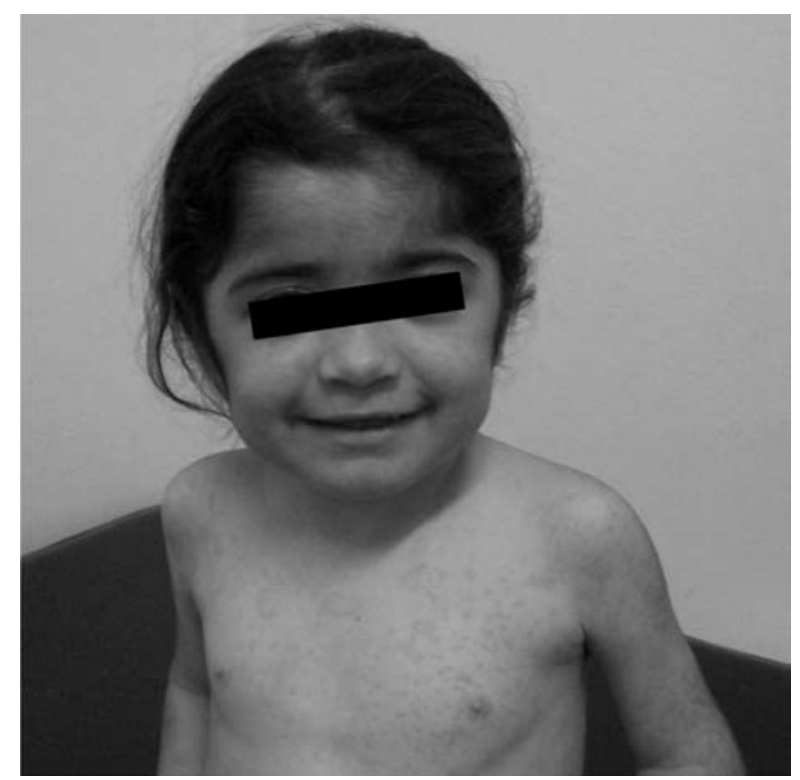

Figura 1 - Exantema cutâneo maculopapular generalizado na paciente em vigência de febre.

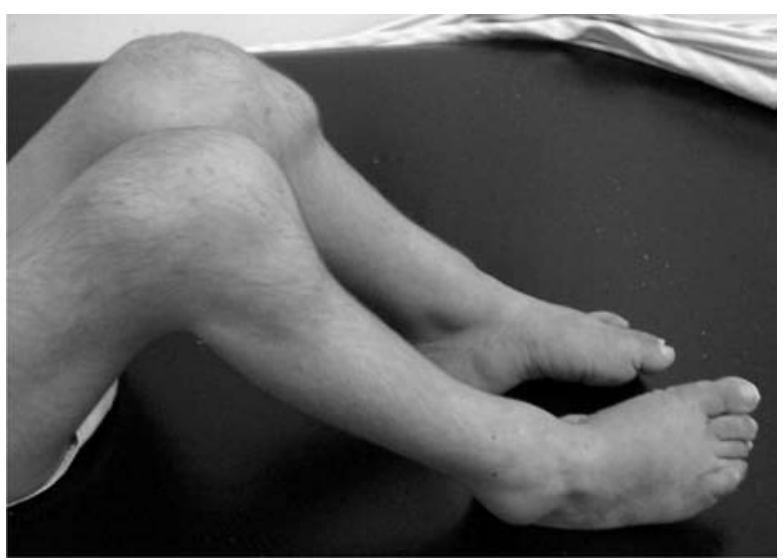

Figura 2 - Aumento de volume em joelhos e tornozelos com importante limitação em flexão e incapacidade funcional.

Nas radiografias dos ossos longos, observaram-se marcada desmineralização óssea, periostite diafisária, encurtamento dos membros inferiores e joelhos em flexão, 
metáfises, cartilagens de conjugação e epífises alargadas em copa, fragmentação principalmente epifisária nas articulações dos joelhos, tornozelos, calcâneos, punhos e cotovelos, além de hipertrofia e fragmentação da patela bilateralmente (Figura 3).

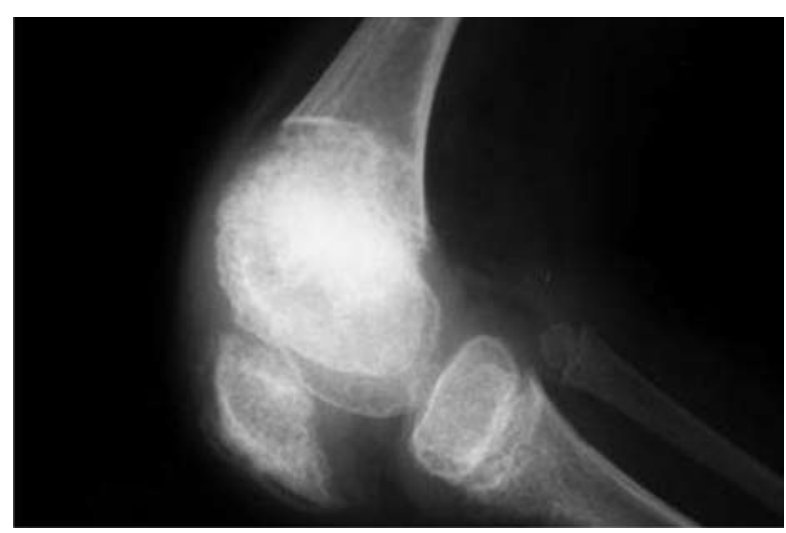

Figura 3 - Radiografia da paciente com limitação do joelho em flexão mostrando fragmentação principalmente epifisária e da patela.

Realizou-se pesquisa genética para síndrome CINCA para verificar mutação no gene CIASI (éxon 3) pelo método de reação em cadeia da polimerase (PCR), tendo sido confirmada a mutação A439P no gene CIAS1. Estabeleceuse o diagnóstico de síndrome CINCA aos 3 anos de idade e iniciou-se tratamento com corticóide via oral (prednisona 1 $\mathrm{mg} / \mathrm{kg} /$ dia) e antiinflamatório não hormonal (naproxeno $15 \mathrm{mg} / \mathrm{kg} /$ dia) com melhora apenas da febre, persistindo os demais sintomas. Seis meses após, associou-se metotrexato na dose de $0,5 \mathrm{mg} / \mathrm{kg} / \mathrm{semana}$, e permanece até o momento com essas medicações. Apresenta melhora das crises de dor, febre e exantema, embora com as limitações da seqüela articular.

A paciente está em uso de órteses em punhos e joelhos e em acompanhamento multidisciplinar, realizando sessões de hidroterapia, fisioterapia motora, fonoaudiologia e terapia ocupacional. Quanto ao exame neurológico, mantém atraso na linguagem, com frases gramaticais e dislalia de troca e compreensão de ordens simples. Senta com apoio, não muda de decúbito, não engatinha nem apresenta controle de esfíncteres. Os reflexos estão presentes e normais, sem comprometimento de pares cranianos. O exame oftalmológico e a audiometria realizados com 3 anos e 6 meses de idade foram normais.

\section{DISCUSSÃO}

A síndrome CINCA é uma doença rara, crônica, que acomete crianças desde os primeiros meses de vida. Como essa doença não está associada a elevações de títulos de auto-anticorpos nem antígenos específicos, não é classificada como uma doença auto-imune clássica, mas autoinflamatória $^{(6,7)}$. O sinal clínico mais precoce da doença, que pode estar presente ao nascimento em $80 \%$ dos casos, é o exantema, do tipo urticariforme, maculopapular, evanescente, de formas irregulares que se exarceba durante a febre e a exposição solar. A febre diária intermitente, dificilmente superior a $39^{\circ} \mathrm{C}$, é uma das primeiras manifestações da doença $a^{(3,12)}$.

O envolvimento articular simétrico da síndrome CINCA pode variar de edema discreto à artropatia destrutiva ${ }^{(15)}$. As articulações mais acometidas são os joelhos (em 100\% dos pacientes), cotovelos e tornozelos, como ocorreu no caso em estudo ${ }^{(3,10,12)}$. Pode afetar ainda articulações das mãos, punhos e pés, com contraturas fibrotendíneas; raramente o esqueleto axial, os ombros e os quadris estão envolvidos $^{(2,13)}$. Em $50 \%$ dos pacientes, a artrite inicia-se no primeiro ano de vida, sendo o prognóstico pior com rápida progressão e incapacidade funcional. Nos $50 \%$ restantes, as alterações articulares são moderadas e não destrutivas, iniciando-se após os 2 anos de idade. Entesopatia associada à tenossinovite em membros inferiores também foi descrita em um caso $^{(6)}$.

O acometimento do sistema nervoso central (SNC) é variável tanto na intensidade quanto na forma, sendo muito frequentes meningite crônica asséptica, cefaléia, macrocrania, calcificações intracranianas, espasticidade, convulsões, diminuição cognitiva, hipotonia e atraso do desenvolvimento neuropsicomotor ${ }^{(2,3,11,13)}$.

Outras manifestações descritas são retardo de crescimento, nariz em sela, dedos grossos e curtos com baqueteamento digital, hepatosplenomegalia, linfonodomegalia, proteinúria, nefrite mesangial e disfunção hepática ${ }^{(2,8,11,13,14)}$. Envolvimento de órgãos sensoriais, incluindo manifestações oculares e surdez progressiva neurossensorial, foi documentado em $22 \%$ dos pacientes ${ }^{(13)}$. Em estudo multicêntrico internacional sobre as manifestações oculares da síndrome CINCA, alterações do disco óptico foram relatadas em $83 \%$ dos pacientes, caracterizadas por edema, pseudopapiledema e atrofia do nervo óptico; uveíte anterior crônica, em 55\%. Perda da acuidade visual em pelo menos um olho e vasculite retiniana foram observadas por outros autores ${ }^{(2,13)}$. 
O diagnóstico da síndrome CINCA é essencialmente clínico. Recentemente muitos avanços têm sido alcançados, com base na medicina molecular e na genética ${ }^{(15)}$. A recorrência familiar sugere o caráter esporádico da doença ${ }^{(1,6)}$. Apesar das semelhanças clínicas com as infecções intra-uterinas ou neonatais, a pesquisa de vírus, fungos, bactérias e imunodeficiências tem sido negativa ${ }^{(4)}$. Causas ambientais, defeitos de neutrófilos, desregulação da função das citocinas e alterações de cartilagem têm sido aventados como etiologia da síndrome $e^{(2,3,8,10)}$. A ativação de alguns marcadores de neutrófilos como o CD10 pode ser a causa das alterações inflamatórias típicas de alguns pacientes com a síndrome $\mathrm{CINCA}^{(5)}$. Estudos anteriores indicaram que os neutrófilos poderiam desempenhar papel central na patogênese da doença ${ }^{(3)}$.

Aproximadamente 50 mutações independentes no gene CIASI (cuja expressão é alta em células polimorfonucleares e condrócitos) ${ }^{(1)}$ foram encontradas, todas afetando o éxon $3^{(7,11,15)}$. A criopirina, produto do gene CIASI, também tem sido implicada na regulação da inflamação mediante a ativação do fator nuclear kappa beta, da regulação de interleucina $1 \mathrm{e}$ de outras citocinas ${ }^{(1,5,7,9,15)}$. Prieur et al. ${ }^{(3)}$ já haviam demonstrado, in vitro, a inibição da proliferação de condrócitos pelo soro de alguns pacientes portadores da doença, sugerindo, como em outros estudos, que a cartilagem seria o órgão-alvo da inflamação na síndrome $\mathrm{CINCA}^{(10)}$.

Nos exames complementares, observam-se anemia hipocrômica, leucocitose com predomínio de neutrófilos e eosinófilos, plaquetose e elevação de provas de fase aguda ${ }^{(2,4,8)}$. A eletroforese de proteínas pode mostrar hipergamaglobulinemia policlonal (IgG, IgM ou IgA ${ }^{(3-5)}$. A dosagem de complemento sérico e de imunocomplexos circulantes não mostra alterações significativas ${ }^{(2,3,8,10)}$. O líquido cerebroespinal geralmente é normal ${ }^{(12)}$, mas pode haver aumento de celularidade $^{(2)}$ principalmente eosinorraquia, e/ou aumento de proteínas ${ }^{(2)}$. $\mathrm{O}$ exame anatomopatológico em medula óssea, fígado, pele e linfonodos demonstra processo inflamatório crônico inespecífico e presença de eosinófilos ${ }^{(3)}$. No exame histológico da membrana sinovial, observa-se também um processo inflamatório discreto com infiltrado perivascular constituído por neutrófilos, eosinófilos e mastócitos. Ocorrem, ainda, necrose focal e proliferação desorganizada de condrócitos ${ }^{(10)}$.

As imagens características da doença que sugerem o diagnóstico são vistas nas extremidades distais dos ossos longos, comprometendo em freqüência decrescente os joelhos, tornozelos, punhos e cotovelos. $\mathrm{O}$ achado radiológico mais consistente nos segmentos envolvidos são as metáfises largas e em copa, cartilagens de conjugação fragmentadas e epífises aumentadas com calcificação irregular. É constante o aumento no volume das patelas, observando-se ossificação prematura e grosseira. Entre as complicações, pode ocorrer fratura óssea espontânea conseqüente à desmineralização óssea. Há relatos de degeneração óssea para condrossarcoma $^{(4,10)}$. As alterações radiográficas ocorrem em aproximadamente metade dos casos durante o primeiro ano de vida. A paciente relatada apresentou as alterações clássicas nos joelhos, tornozelos, punhos, cotovelos $\mathrm{e}$ fragmentação das epífises dos calcâneos. A RM das articulações mostra aumento no volume, sem comprometimento sinovial importante ${ }^{(4,8,10)}$.

Fontanelas amplas, com retardo no fechamento e ossos wormianos, podem ser vistas na radiografia do crânio. A TC e RM de crânio freqüentemente são normais, porém podem mostrar alargamento ventricular com atrofia cerebral e aumento dos fluidos nos espaços extra-axiais, calcificações da foice e dura-máter ${ }^{(2,12)}$.

O principal diagnóstico diferencial a ser feito é com a artrite idiopática juvenil (AIJ $)^{(10,11)}$ e a da forma sistêmica, pois ambas são de diagnóstico essencialmente clínico e apresentam aumento das provas inflamatórias, leucocitose, plaquetose e anemia. Neste subtipo ocorrem surtos febris e exantema cutâneo típico. As lesões são maculopapulares eritematosas e fugazes, afetando todo o corpo, mas mais localizadas em tronco e membros e exarcebam durante os picos febris. A artrite é, geralmente, poliarticular, simétrica e aditiva, acometendo tanto grandes como pequenas articulações. O exame radiológico pode ajudar a diferenciá-la. A principal diferença radiológica é que na síndrome CINCA as alterações ocorrem nas cartilagens de crescimento, epífises e patelas, enquanto as lesões da AIJ comprometem as superfícies articulares ${ }^{(3)}$. Outra diferença é que o envolvimento do SNC e o retardo mental peculiares à síndrome CINCA não ocorrem na $\mathrm{AIJ}^{(4,10)}$.

Os outros diagnósticos diferenciais devem ser feitos com doenças do período neonatal, como infecções crônicas intra-útero, hipergamaglobulinemia $\mathrm{D}$ (que pode cursar com artrite, febre e exantema), síndrome de Sweet (dermatose neutrofilica febril), FAPA (febre periódica, adenopatia, faringite e estomatite aftosa), histiocitose, mastocitose, rubéola neonatal de início tardio, síndrome de Muckle-Wels (exantema urticariforme, artrite e surdez), Wissler Fanconi e febre familiar do Mediterrâneo ${ }^{(3,11,12)}$.

O tratamento é, freqüentemente, empírico, pois ainda não existe consenso. Antiinflamatórios não hormonais e corticoesteróides têm sido utilizados com resultados 
variáveis ${ }^{(3,4,14)}$. Os corticoesteróides têm se mostrado eficazes no alívio da dor e dos picos febris, como ocorreu no caso descrito, mas sem modificação das provas inflamatórias, das alterações cutâneas e articulares. Alguns autores têm utilizado precocemente drogas imunossupressoras, como metotrexato, ciclofosfamida, clorambucil, D-penicilamina, ciclosporina $^{(12)}$, azatioprina ${ }^{(2,10)}$ e sais de ouro, e imunomoduladores (gamaglobulina endovenosa), com o objetivo de bloquear a evolução da doença, diminuir a atividade inflamatória, permitir o crescimento e desenvolvimento adequado da criança e diminuir seqüelas ${ }^{(4)}$. Entretanto, ainda não se tem evidências de que esses medicamentos modifiquem a evolução da doença ${ }^{(2-4,10)}$. A regulação pela CIAS1 sugere que um bloqueador de receptor de interleucina 1 possa constituir um tratamento eficaz, entretanto mais estudos são necessários para melhor identificar essa via antiinflamatória ${ }^{(1,7,14)}$. A terapia biológica está em estudo experimental; o etarnecept foi usado recentemente em uma criança de 4 anos de idade, por 6 meses, com melhora importante do quadro articular e diminuição da freqüência dos episódios febris, sugerindo o provável papel do TNF alfa (fator de necrose tumoral alfa) na fisiopatologia da doença ${ }^{(14)}$. A fisioterapia com hidroterapia e a terapia ocupacional com uso de órteses constituem parte importante no tratamento dessa doença ${ }^{(2,4)}$.

O prognóstico da síndrome CINCA é pior em pacientes que apresentam a doença no período neonatal. Alguns autores sugeriram que a severidade dos sintomas poderia ser influenciada pelos locais de mutação no gene CIASI ${ }^{(9)}$. $\mathrm{O}$ curso progressivo natural da doença é típico, levando

\section{REFERÊNCIAS}

1. Feldmann J, Prieur AM, Quartier P, Berquin P, Certain S, Cortis E et al.: Chronic infantile neurological cutaneous and articular syndrome is caused by mutations in CIAS1, a gene expressed in polymorphonuclear cells and chondrocytes. Am J Hum Genet 71: 198-203, 2002.

2. Russo RA, Katsicas MM: Chronic infantile neurological cutaneous and articular syndrome: two new cases with rare manifestations. Acta Paediatr 90 (9): 1076-9, 2001.

3. Prieur AM, Griscelli C, Lampert F, Truckenbrodt H, Guggenheim MA, Lovell DJ, et al.: A chronic, infantile, neurological, cutaneous, and articular (CINCA) syndrome. A specific entity analysed in 30 patients. Scand J Rheumatol Suppl 66: 57-68, 1987.

4. Prieur AM: A recently recognised chronic inflammatory disease of early onset characterised by the triad of rash, central nervous system involvement and arthropathy. Clin Exp Rheumatol 19: 103-6, 2001. à incapacidade motora e adaptativa ${ }^{(14)}$. Incapacidade funcional significativa ocorre em mais de $50 \%$ dos pacientes. Em $100 \%$ das crianças, ocorre retardo de desenvolvimento pôndero-estatural. O óbito ocorre na adolescência ou no adulto jovem em $20 \%$ dos pacientes por infecção, complicações neurológicas ou por amiloidose secundária ${ }^{(3,6,12)}$.

Em virtude de a etiologia e a fisiopatologia da síndrome CINCA permanecerem incertas e sendo poucos os casos relatados na literatura mundial, há dificuldade na padronização dos critérios diagnósticos e tratamento. Este relato de caso tem como objetivo alertar o reumatologista para este diagnóstico diferencial da AIJ sistêmica que, apesar de raro, pode acarretar incapacidade funcional severa. O diagnóstico e a instituição terapêutica mais precoce podem minimizar as seqüelas. Os constantes avanços da medicina genética poderão melhorar a prevenção e o tratamento da síndrome CINCA.

\section{AGRADECIMENTOS}

Agradecemos à família da paciente envolvida no estudo pela cooperação. Somos gratas ao excelente trabalho voluntário realizado pela fisioterapeuta Dra. Silvania Cardinal, ao Dr. Salmo Raskin, especialista em Genética Médica, responsável pelo Laboratório GENETIKA, que encaminhou o exame de PCR (reação em cadeia da polimerase) sem custo ao Laboratoire de Genetique Moleculaire et Chromosomique e à Dra. I Touitou, que também sem nenhum custo realizou o exame genético de excelente qualidade técnica.

5. Leone V, Presani G, Perticarari S, Tommasini A, Crovella S, Lenhardt A, et al.: Chronic infantile neurological cutaneous articular syndrome: CD10 over-expression in neutrophils is a possible key to the pathogenesis of the disease. Eur J Pediatr 162: 669-73, 2003.

6. Gámir Gámir ML, Navío Marco MT: Sindrome cinca y entesopatía. Na Esp Pediatr 51: 208-9, 1999.

7. Aksentijevich I, Nowak M, Mallah M, Chae JJ, Watford WT, Hofmann SR: De Novo CIASI mutations, cytokine activation, and evidence for genetic heterogeneity in patients with NeonatalOnset Multisystem Inflammatory Disease (NOMID). Arthritis Rheum 46 (12): 3340-8, 2002.

8. Kaufman Ra, Lovell DJ: Infantile-onset multisystem inflammatory disease: radiologic findings. Radiology 160: 741-6, 1986.

9. Rösen-Wolff A, Quietzsch J, Schröder H, Lehmann R, Gahr M, Roesler J: Two german CINCA (NOMID) patients with different clinical severity and response to anti-inflammatory treatment. Eur J Haematol 71: 215-9, 2003. 
10. De Cunto CL, Liberatore DI, San Roman JL, Goldberg JC, Morandi AA, Feldman G: Infantile-onset multisystem inflammatory disease: a differential diagnosis of systemic juvenile rheumatoid arthritis. J Pediatr 130(4): 551-6, 1997.

11. Silvestri LA, Hayata ALS, Abreu AC, Mazetto AR, Bucchianeri MS, Kochen JAL, et al.: Síndrome CINCA: uma rara e grave manifestação de poliartrite da infância. Rev Bras Reumatol 40 (4): 209-12, 2000.

12. Carvalho MFF. Síndrome CINCA. In: Knupp S (ed.). Reumatologia pediátrica. 3. ed. Rio de Janeiro: Atheneu, 2002. pp. 607-10.

13. Dollfus H, Hafner R, Hofmann HM, Russo RAG, Denda L, Gonzales LD, et al.: Chronic infantile neurological cutaneous and articular/neonatal onset multisystem inflammatory disease syndrome: ocular manifestations in a recently recognized chronic inflammatory disease of childhood. Arch Ophthalmol 118 (10): 1386-92, 2000.
14. Federico G, Rigante D, Pugliese AL, Ranno O, Catania S, Stabile A: Etanercept induces improvement of arthropathy in chronic infantile neurological cutaneous articular (CINCA) syndrome. Scand J Rheumatol 32 (5): 312-4, 2003.

15. Neven B, Callebaut I, Prieur AM, Feldman J, Bodemer C, Lepore L, et al.: Molecular basis of the spectral expression of CIAS 1 mutations associated with phagocytic cell-mediated autoinflammatory disorders CINCA/NOMID, MWS, and FCU. Blood 103 (7): 2809-15, 2004.

16. Petty RE, Southwood TR, Baum J, Bhettay E, Glass DN, Manners P, et al.: Revision of the proposed classification criteria for juvenile idiopathic arthritis: Durban, 1997. J Rheumatol 25: 1991-4, 1998.

17. Petty RE, Southwood TR, Manners P, et al. International League of Associations for Rheumatology classification of juvenile idiopathic arthritis: second revision (Edmonton, 2001). J Rheumatol 31: 390-2, 2004. 